\title{
Computational design studies for an ion extraction system for a "volume- type" ECR ion source
}

\author{
H. Zaim ${ }^{1}$ and G. D. Alton, \\ Oak Ridge National Laboratory, ${ }^{2}$ P.O. Box 2008, Oak Ridge, TN 37831-6368, USA
}

Numerical studies have been performed for optimally extracting high-intensity, space-chargedlimited multi-charged ion beams from an all-permanent-magnet, "volume-type" ECR ion source, equipped with a three-electrode extraction system. These studies clearly demonstrate the importance of being able to adjust the extraction gap in order to ensure high quality, minimum divergence (highly transportable) ion beams. Optimum extraction conditions are reached whenever the plasma meniscus has an optimum curvature for a given current density. Optimum perveance (optimum current) values are found to closely agree with those derived from elementary analytical theory for extraction of space-charge-dominated beams. Details of the electrode system design as well as angular divergence and RMS emittance versus extraction parameter data (e.g., perveance and extraction gap) are provided for ion beams of varying charge-state and mass, extracted under the influence of a mirror-geometry plasma confinement magnetic field.

\section{INTRODUCTION}

The advent of sophisticated computational techniques for simulating the actions of electric and magnetic fields on the motions of charged-particle beams under their influence has greatly

\footnotetext{
${ }^{1}$ Ph.D. Graduate Student, Université de Versailles-Saint-Quentin, Versailles, France.

${ }^{2}$ Managed by UT-Battelle, LLC, for the U.S. Department of Energy under contract DE-AC05OOOR22725.
} 
facilitated the design of low-aberration systems for use in their acceleration and transport. These codes have been employed to design a variety of beam transport components, including, lenses, magnets, steerers, deceleration/acceleration electrode systems, etc., and to simulate ion extraction from solid and plasma emitters. Among the computer codes for simulating the extraction of space-charge-dominated ion beams from plasma ion sources are those described in Refs. [1-5]. PBGUNS [3] was used in the present study to simulate extraction of mA intensity levels of multi-charged ion beams from a new concept [6] all-permanent-magnet ECR ion source under development at the Oak Ridge National Laboratory [7]. A more detailed account of this work can be found in Ref. [ 8].

Space-charge effects resulting from the collective influences of charge-density, $\rho$, on individual particle trajectories are simulated by solving Poisson's equation,

$$
\nabla^{2} \phi=-\rho / \varepsilon_{0}
$$

for the potential distribution, $\phi$, at each point within the electrode configuration where $\varepsilon_{0}$ is the permitivity of free space.

\section{THE REMOTELY POSITIONABLE EXTRACTION ELECTRODE SYSTEM}

Figure 1 displays a close-up of the three-electrode extraction system, consisting of a focus (plasma) electrode at potential, $\phi_{s}$, machined into the ion extraction region of the source, an 
extraction (accelerating) electrode at potential, $\phi_{\mathrm{ex}}$, and a ground-potential electrode at potential,

$\phi_{\mathrm{g}}=0$. The extraction gap, $d$, (distance between the ion emission aperture (plasma electrode) and the extraction electrode) can be varied as required for optimization of beam extraction whereas the spacing between the extraction and the ground electrode is fixed (gap: $10 \mathrm{~mm}$ ). The extraction and ground are mechanically attached to each other by means of a ceramic insulator and are mounted, as an assembly, on a remotely positionable miter-gear-driven carriage. The extraction gap, $d$, can be varied between 0.0 and $25.0 \mathrm{~mm}$ along the extraction axis by moving the assembly relative to the plasma electrode to optimize the electric field strength, during ion extraction.

\section{ELEMENTARY EXTRACTION OPTICS: ANALYTICAL THEORY}

\section{A. Langmuir-Blodgett formalism}

Solutions to Poisson's equation (1) for space-charge-limited flow between concentric spherical electrodes can be represented by the Langmuir-Blodgett approximation [8]. Figure 2 illustrates a simplified two-electrode system for the extraction of convergent positive-ion beams from a concave plasma-emission boundary (sector angle: $\theta$, spherical radius: $r_{s}$, and circular emission aperture: a), to a spherical geometry extraction electrode (spherical radius: $r_{e x}$, and aperture radius: $b$ ). Extraction is effected between the source at potential, $\phi_{s}$, and the extraction electrode, at potential, $\phi_{\mathrm{ex}}$, separated by a distance $\Delta z=d=r_{s}-r_{e x}$. 
The appropriate equation for space-charge-limited flow of electrical current, $I$, of a beam of particles of charge-state, $q$, and mass, $M$, in a spherical sector electrode system, maintained at a potential difference, $\Delta \phi_{\mathrm{ex}}$, is given by:

$$
I \cong\left(8 \pi \varepsilon_{0} / 9\right)(2 q / M)^{1 / 2} \Delta \phi_{e x}^{3 / 2}(1-\cos \theta) /(-\alpha)^{2}
$$

where $\varepsilon_{0}$ is the permittivity of free space and a is a dimensionless parameter. a can be shown to be a solution to a non-linear differential equation expressed in series. solution by:

$$
-\alpha=-\mu+0.3 \mu^{2}-0.075 \mu^{3}+0.00143 \mu^{4}
$$

where $\mu=\ln \left(r_{s} / r_{e x}\right)$. The series is valid for $r_{s} / r_{e x}>1$. Tabulations of the function a can be found in several references, including Ref. [9].

The perveance, $P$, for the system is defined as:

$$
\begin{aligned}
P & =I / \Delta \phi_{e x}^{3 / 2} \\
& \cong\left[\left\{4 \varepsilon_{\rho} / 9\right\}(2 \mathrm{e} / \mathrm{M})^{1 / 2} \pi \mathrm{a}^{2} / \mathrm{d}^{2}\right]\left[2(1-\cos \theta) \mathrm{d}^{2} / \mathrm{a}^{2}(-\alpha)^{2}\right] \\
& =2 \mathrm{P}_{\mathrm{pp}}\left[(1-\cos \theta) \mathrm{d}^{2} / \mathrm{a}^{2}(-\alpha)^{2}\right]
\end{aligned}
$$

where $P_{p p}$ is the perveance for extraction of space-charge-limited ion beams in a planar geometry electrode system, as first derived by Child [10], and independently by Langmuir [1 1]. After expansion of Eq. (4), to order $d / r_{s}$ for $d<<r_{s}$, the following approximation is obtained (see, e.g., Ref. 8) :

$$
\mathrm{P}=\mathrm{I} / \Delta \phi_{\mathrm{ex}}^{3 / 2} \cong \mathrm{P}_{\mathrm{pp}}\left(1-1.6 \mathrm{~d} / \mathrm{r}_{\mathrm{s}}\right)
$$

\section{B. Minimum half-angular divergence}

The beam, of convergence angle, $\theta$, arrives on the other side of the aperture in the second

electrode with final half-angular divergence, $\omega$, after having been transmitted through the 
aperture of the extraction electrode. The aperture effect is illustrated by changes in half-angular divergence of the beam, $\psi$, so that the final half-angular divergence is $\omega=\theta-\psi$. The respective half-angular divergences for the electrode system, displayed in Fig. 2, can be shown to be ( e.g., see Ref. 8):

$$
\begin{gathered}
\psi \cong b / 3 d \cong(a / d-\theta) / 3 \\
\theta \cong 0.625\left(1-P / P_{p p}\right) a / d \\
\omega=\theta-\psi \cong\left(1-1.67 \mathrm{P} / P_{p p}\right) a / d
\end{gathered}
$$

These expressions serve to illustrate how the final half-angular divergence, $\omega$, is affected through changes in emission aperture, a, and plasma boundary, $r_{s}$, which are in turn affected by changes in plasma density, and magnitude of the electric field, used for ion extraction.

\section{Optimum perveance}

From Eq. 8, it is evident that $\omega$ versus $P$ should reach a minimum whenever the perveance $P_{\text {opt }}$ has the optimum value $P_{\text {popt }}$ given by:

$$
\mathrm{P}_{\mathrm{popt}} \cong \mathrm{P}_{\mathrm{pp}} / 1.67 \cong 0.6 \mathrm{P}_{\mathrm{pp}}
$$

for a planar geometry electrode system.

\section{SIMULATION STUDIES}

A series of simulation studies were made in order to determine optimum conditions for extraction of space-charge-dominated $\Sigma \mathrm{Ar}^{\mathrm{q}+}$ beams assuming the charge-state distribution given in Ref. 12. To account for magnetic-field influences, the actual magnetic-field distribution for the 
source described in Ref. [7] was used. The curvature of the plasma-emission surface tends to converge/diverge extracted ion beams. Highest quality beams result whenever the plasmaemission boundary is concave and has an optimum radius of curvature. The optimum radius of curvature can be achieved by carefully balancing the plasma density in relation to the strength of the electric field. Under this condition, the angular divergence is minimum. The ability to adjust the extraction gap, $d$, permits optimization of the beam quality over a wide range of plasma densities, charge-state distributions and ion species without having to change the final energy of the beam, Figure 3 displays profiles of $\Sigma \mathrm{Ar}^{\mathfrak{q}^{+}}$beams and their RMS emittances for an electrode position too close to the source, for an optimum electrode setting, and for an electrode system too far from the source. As clearly illustrated, the curvature of the ion-emission boundary is critically dependent on the position of the extraction electrode relative to the emission aperture for fixed plasma density, charge-state distribution, and extraction-potential difference.

Figure 4 displays optimum extraction gap versus charge-state for beams of $\mathrm{Ar}^{+}, \Sigma \mathrm{Ar}^{\mathrm{q}+}$ and $\mathrm{Ar}^{11+}$.

The optimum extraction gap, $d_{\text {opt }}$, increases with charge-state, $q$, or average charge-state $<q>$ according to theory $\left(d, \propto \propto q^{1 / 4}\right)$. The mass effect is clearly apparent in Fig. 5, which shows separate and distinct values for the perveance, $P \propto(1 / M)^{1 / 2}$ as predicted from theory.

\section{CONCLUSIONS}

These studies clearly demonstrate the necessity of providing means for varying the extraction gap for assuring high quality space-charge-dominated beams. The results derived from the 
simulations of the extraction optics agree closely with those predicted from elementary extraction theory. A remotely positionable electrode system, such as described in this article, provides a preferred means for extracting high quality beams of a broad spectrum of multicharged ions over a wide range of plasma densities.

\section{REFERENCES}

1. J. C. Whitson, J. Smith and J. H. Whealton, J. Comp. Phys. 28 (1978) 408.

2. J. H. Whealton, M. A. Bell, R. J. Raridon, K. E. Rothe and P. M. Ryan, J. App Phys. 64 (1988) 6210.

3. J. E. Boers, A digital computer code for the simulation of electron and ion beams on a PC, IEEE Cat. No. 93CH3334-0 (1993) 213. (PBGUNS is an electron/ion optics simulation code, developed by Thunderbird Simulations, Garland, TX, USA).

4. P. Spädtke, AXCEL-GSI, Interaktives Simulations programm zur Berechnung von zwiedimensionalen Potentialverteilungen electrostatischer Anordnungen sowie von Ionbahnen in electrostatischen Feldern unter Berncksichtigung der Raumladung, GSIReport 9 (1983).

5. R. Becker and W. B. Herrmannsfeldt, IGUN-A program for the simulation of ion extraction, including magnetic fields, Rev. Sci. Instrum. 63 (1992) 2756.

6. G. D. Alton and D. N. Smithe, Rev. Sci. Instrum. 65 (1994) 775.

7. Y. Liu, G. D. Alton, C. A. Reed and D. L. Haynes, Rev. Sci. Instrum. 69 (1998) 1311.

8. G. D. Alton and H. Zaim, to be published in Phys. Rev. Special Topics, 2001.

9. I. Langmuir and K.R. Blodgett, Phys. Rev. 24 (1924) 49.

10. C. Child, Phys. Rev. 31 (1911) 492. 
11. I. Langmuir, Yhys. Rev. 2 (1913) 450.

12. A. Heinen, et al., Rev. Sci. Instrum. 69 (1998) 729.

\section{FIGURE CAPTIONS}

Fig. 1: Schematic drawing of the moveable three-electrode extraction system.

Fig. 2: Simplified spherical geometry, two-electrode system for ion extraction from a-concave plasma boundary.

Fig. 3: Beam profiles and RMS emittances of $\Sigma \mathrm{Ar}^{\mathrm{q}+}$ beams extracted from the three-electrode extraction system with the extraction gap, $d$ : a) too close to the source; b) optimally positioned; c) too far from the source.

Fig. 4: Half-angular divergence, $\omega$, versus extraction gap, $d$, for beams of $\mathrm{Ar}^{+}, \Sigma \mathrm{Ar}^{\mathrm{q}^{+}}$and $\mathrm{Ar}^{1+}$. Beam Intensity: $2.2 \mathrm{~mA} ; \Delta \phi_{\mathrm{ex}}: 13.1 \mathrm{kV}$; Beam Energy: $20<\mathrm{q}>\mathrm{keV}$.

Fig. 5: Half-angular divergence, $\omega$, versus extraction gap, $d$, for beams of $\mathrm{He}^{\prime}(4.5 \mathrm{~mA}), \mathrm{Ne}^{+}(2.0$ $\mathrm{mA}), \mathrm{Ar}^{+}(1.45 \mathrm{~mA}), \mathrm{Kr}^{+}(1.0 \mathrm{~mA}), \mathrm{Xe} \mathrm{e}^{\prime}(0.8 \mathrm{~mA})$ and $\mathrm{Rn}^{+}(0.6 \mathrm{~mA})$. 


\section{FIGURES}

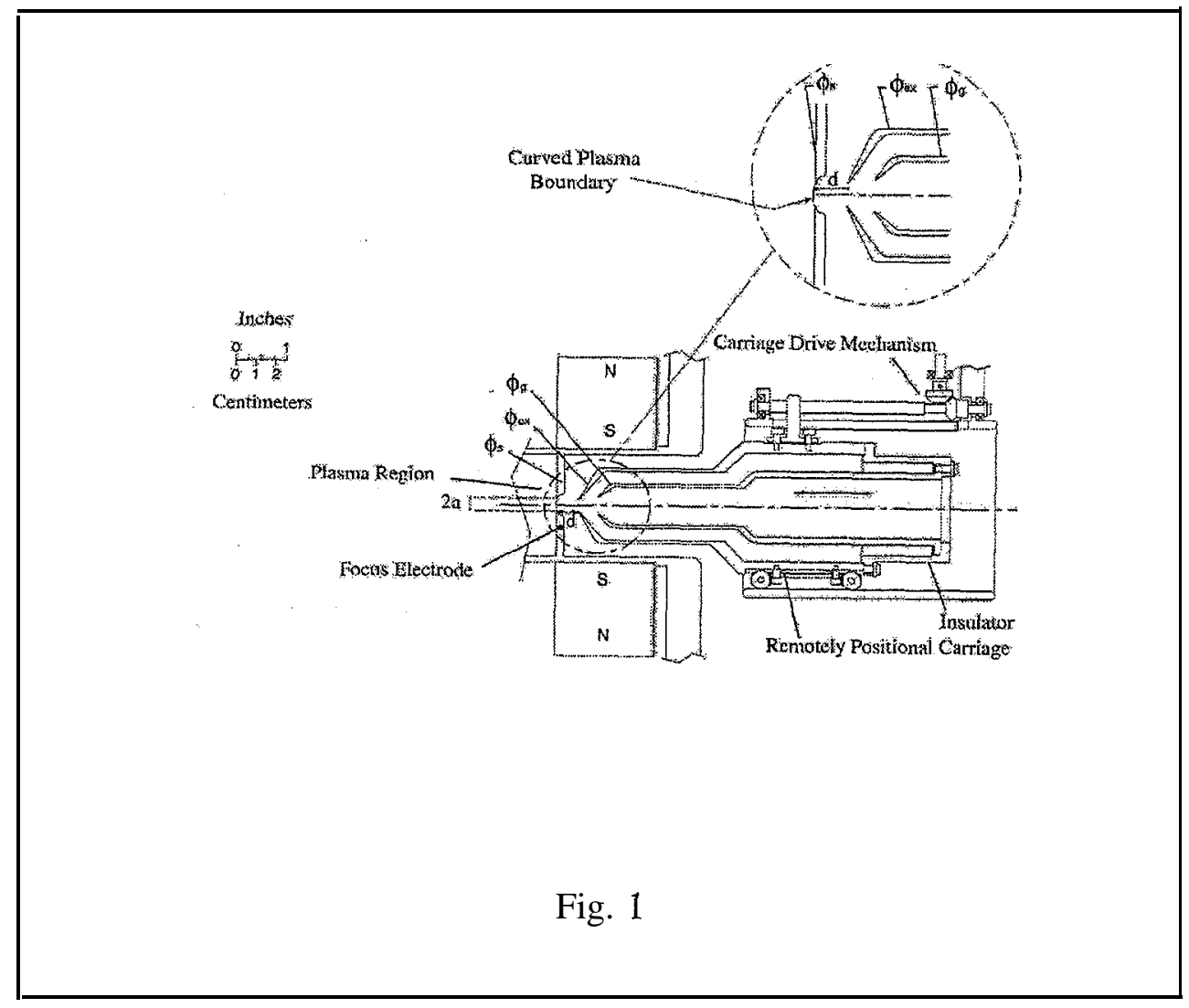




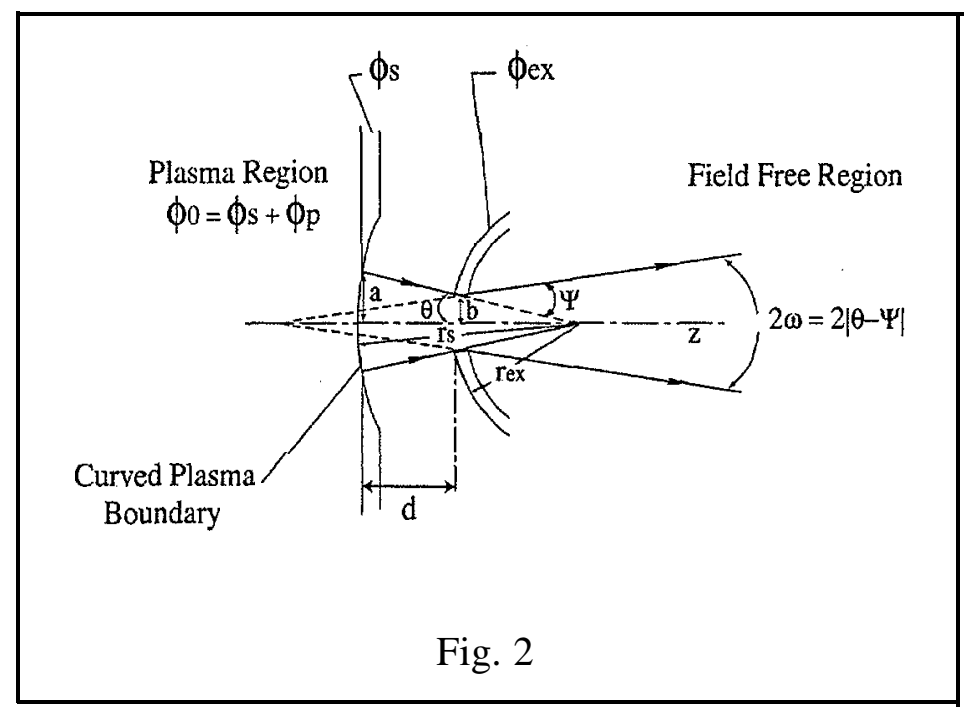




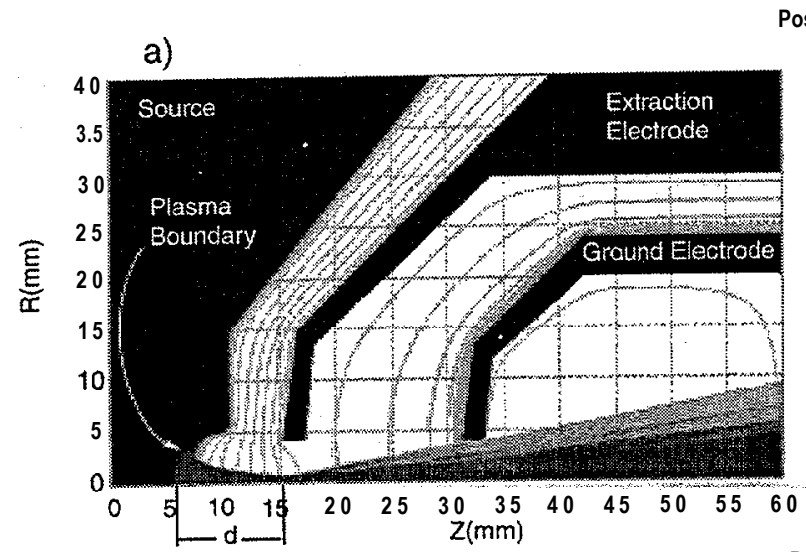

Position 1

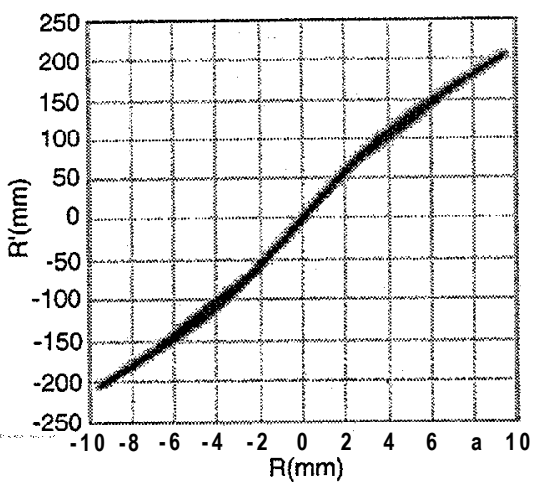

b)

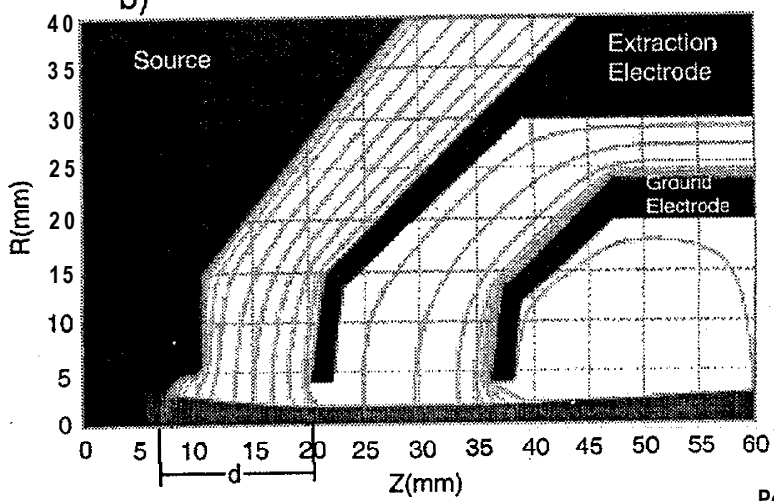

sition 2

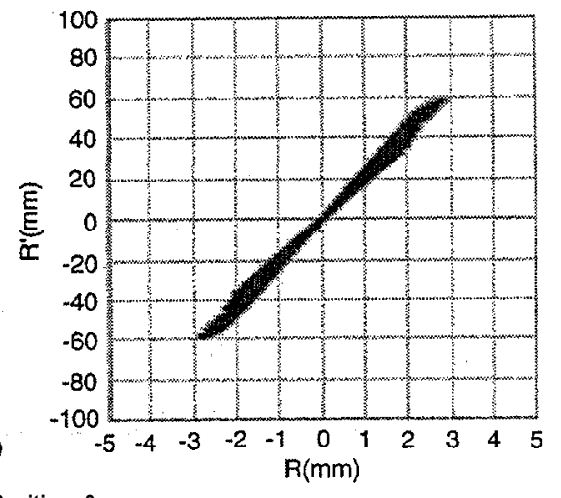

c)
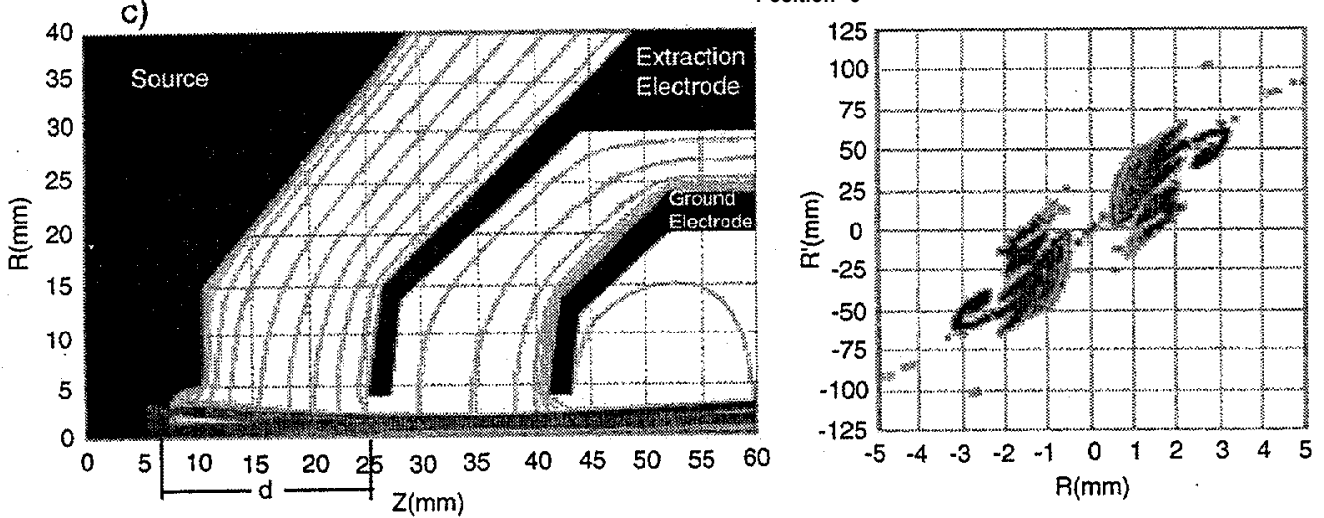

Fig. 3 


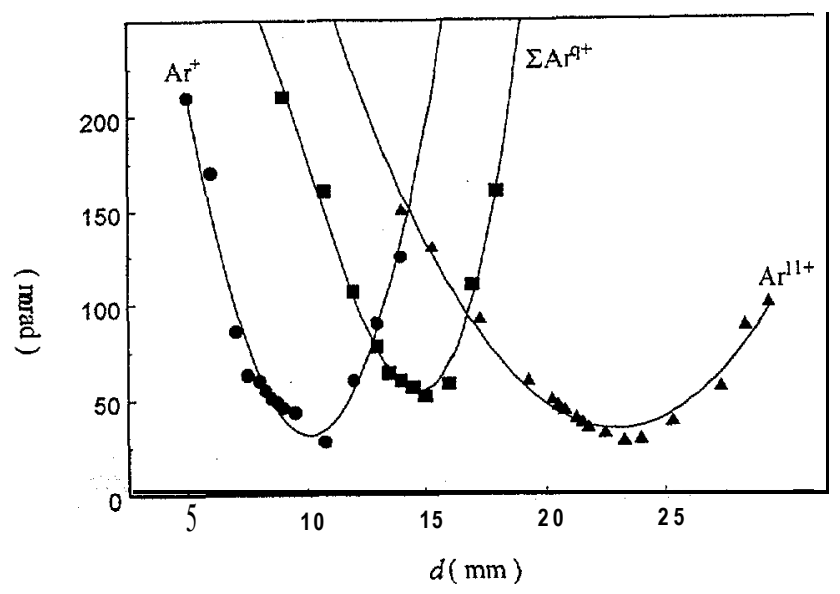

Fig. 4 


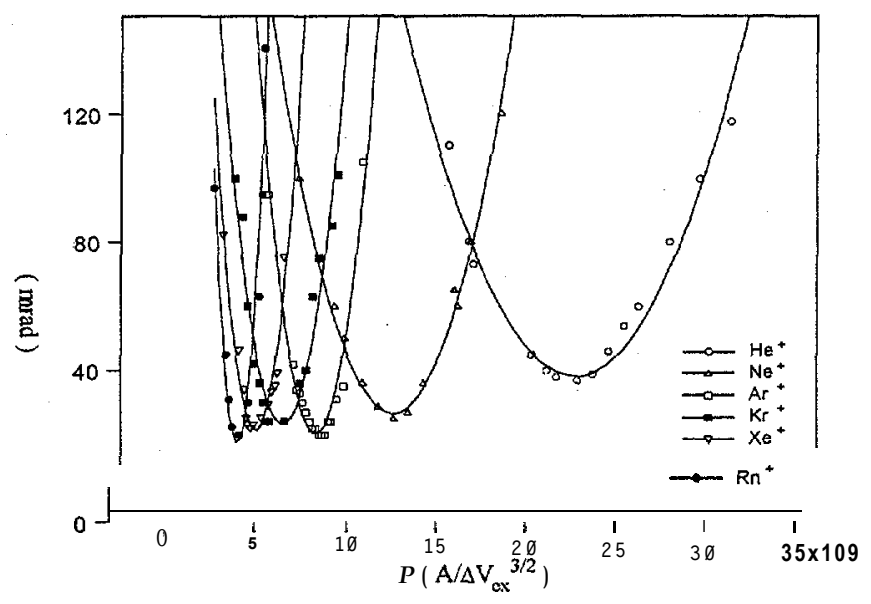

Fig. 5 